\title{
A quadricuspid aortic valve causing moderate aortic regurgitation
}

\author{
Eftal Murat Bakirci, Sakir Arslan, Husnu Degirmenci, Serdar Sevimli \\ Department of Cardiology, Faculty of Medicine, Atatürk University, Erzurum, Turkey
}

\begin{abstract}
Quadricuspid aortic valve $(Q A V)$ is a rare cause of aortic regurgitation. Most cases are detected incidentally during echocardiography, angiography, autopsy or surgery. It may also be associated with other congenital anomalies of the heart. A 70 year-old man was admitted to our hospital with a five-month history of dyspnea. Echocardiographic examination showed a QAV leading to moderate aortic regurgitation, severe mitral regurgitation, left ventricular dysfunction and aortic root dilatation. Surgical treatment was considered, but the patient refused. We describe a case of QAV leading to aortic regurgitation. (Cardiol J 2012; 19, 6: 632-634)
\end{abstract}

Key words: aortic regurgitation, echocardiography, quadricuspid aortic valve

\section{Introduction}

A quadricuspid aortic valve (QAV) is an uncommon congenital anomaly [1] and it is often detected incidentally. The first case of QAV was reported in 1862 [2]. Since then, approximately 200 cases have been reported in the literature [3]. Aortic regurgitation is the most frequent valvular dysfunction in patients with a QAV, whereas valvular stenosis is very rare [3]. Echocardiographic examination plays an important role in the diagnosis. We report a case of QAV leading to aortic regurgitation.

\section{Case report}

A 70 year-old man was admitted to our hospital with a five-month history of dyspnea (NYHA class III). The patient had no cardiovascular disease risk factors. Initial physical examination revealed blood pressure of $120 / 80 \mathrm{~mm} \mathrm{Hg}$, respiratory rate of $23 / \mathrm{min}$, and a pulse rate of $85 / \mathrm{min}$. On cardiac auscultation, heart sounds were soft and $2-3 / 6$ diastolic murmur was heard at the left sternal border. The respiratory sounds on auscultation were nor- mal. The electrocardiogram showed atrial fibrillation. Chest X-ray showed cardiomegaly. The hemogram and biochemical parameters were all found to be normal. The transthoracic echocardiogram (TTE) showed left ventricular enlargement (end-diastolic and end-systolic diameters, respectively, of 60 and $42 \mathrm{~mm}$ ), left ventricular dysfunction (ejection fraction: $38 \%$ ), severe mitral regurgitation and moderate aortic regurgitation without the usual Y-aspect trileaflet closure (Fig. 1). The aortic valve appeared abnormal and possibly quadricuspid (Fig. 2). Real-time three-dimensional echocardiography (RT3DE) and transesophageal echocardiography (TEE) were performed for a detailed examination of the aortic valve. These revealed a $\mathrm{QAV}$ with an $\mathrm{X}$-shaped commissural aspect in diastole, which consisted of three cusps of equal size and one smaller accessory cusp (type $b$ according to the Hurwitz and Roberts classification of QAVs) (Figs. 3, 4). The smaller cusp was located between the non-coronary and right coronary cusps. There was a moderate central aortic regurgitation due to an abnormal coaptation of the cusps. The ascended aorta was enlarged (diameter: $52 \mathrm{~mm}$ ). No other cardiac abnor-

Address for correspondence: Eftal Murat Bakirci, MD, Atatürk Üniversitesi Tip Fakültesi, Kardiyoloji Anabilim Dali, Erzurum, Turkey, tel: +90 44231663 33, e-mail: eftalka@yahoo.com

Received: 30.01.2011 Accepted: 12.08.2011 


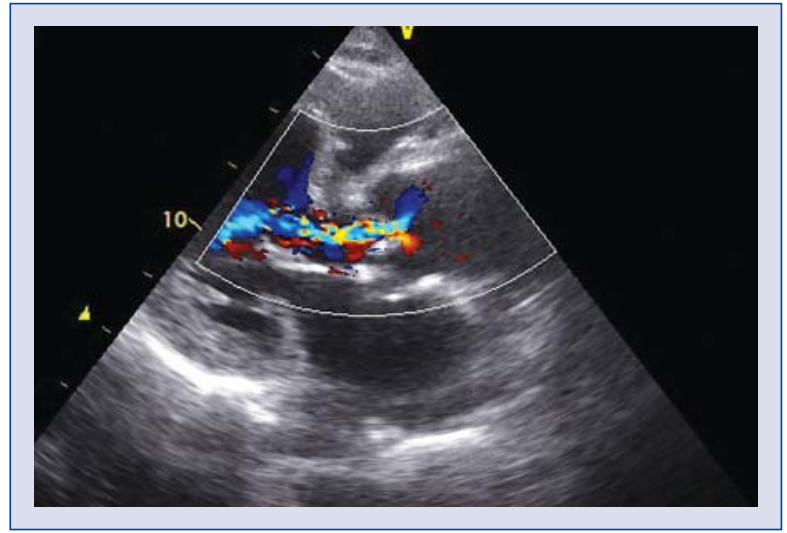

Figure 1. Transthoracic color Doppler echocardiography showing moderate aortic regurgitation (regurgitan volume: $38 \mathrm{~mL}$ ).

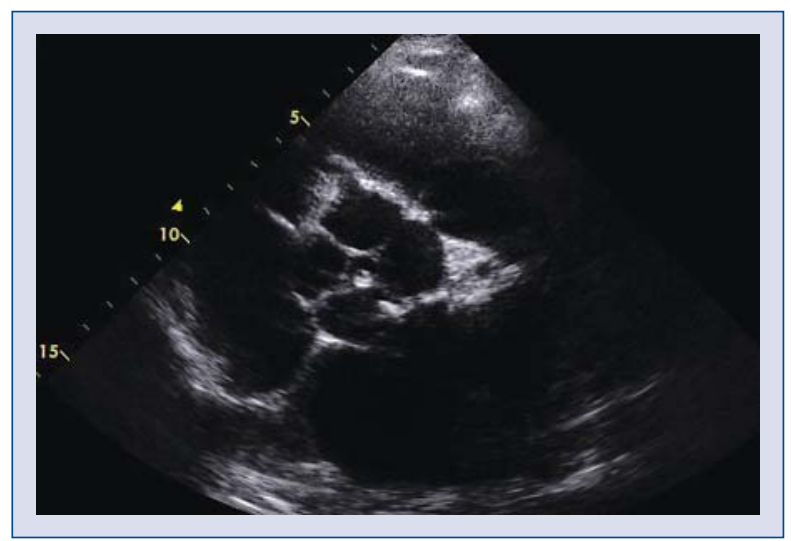

Figure 2. Two-dimensional transthoracic short-axis view of the aortic valve.

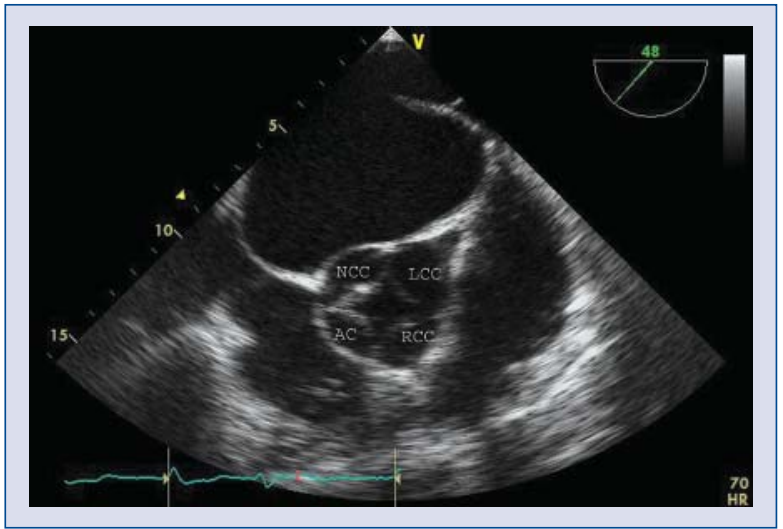

Figure 3. Two-dimensional transesophageal short-axis view of the aortic valve; AC - accessory cusp; LCC left coronary cusp; NCC - non-coronary cusp; RCC right coronary cusp.

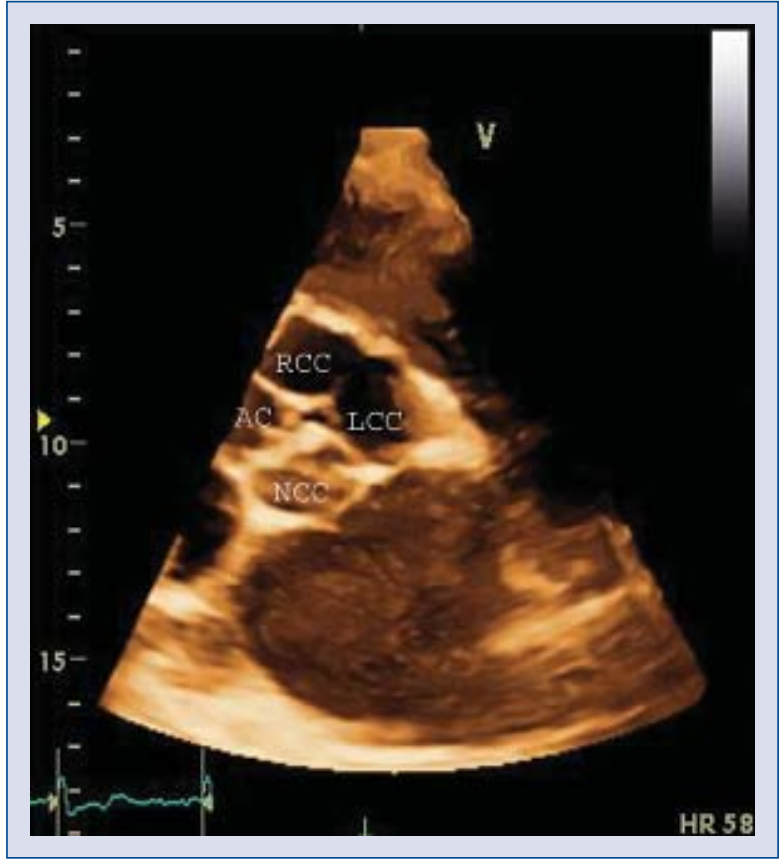

Figure 4. Three-dimensional transthoracic short-axis view of the aortic valve; AC - accessory cusp; LCC left coronary cusp; NCC - non-coronary cusp; RCC right coronary cusp.

mality was found. The coronary angiogram was normal. In the present case, surgical treatment was considered, but the patient refused. Medical treatment was initiated.

\section{Discussion}

QAV is a very rare form of congenital valvular malformation with a reported incidence ranging from $0.008 \%$ to $0.033 \%$ [1]. Most cases are discovered incidentally during echocardiography, angiography, autopsy or surgery. Its mechanism is not fully understood. One of the leading hypotheses is for an abnormal septation of the embryological arterial trunk [4]. The mean age of diagnosis is 49 years and the diagnosis is more frequent in male patients $[3,5]$.

Hurwitz and Roberts [1] introduced a classification nomenclature for QAV that included seven different types named $a$ to $g$. The type described in this case, with three equal cusps and one smaller, is type $b$ ( $b$ type in the Hurwitz and Roberts classification being the commonest one).

Aortic regurgitation is the predominant valvular dysfunction associated with QAV, whereas val- 
vular stenosis is very rare [3]. The abnormal leaflet coaptation, fibrous thickening and asymmetric mechanical stress around the four cusps leads to aortic regurgitation, which also increases the risk of endocarditis [6]. Other cardiac defects associated with QAV include ventricular septal defect, subaortic fibromuscular stenosis, patent ductus arteriosus, coronary ostium displacement and altered coronary artery anatomy [7].

Aortic valve replacement for a $\mathrm{QAV}$ is generally the treatment of choice for severe valvular regurgitation. Only a few cases of aortic valve repair have been reported [8]. Surgeons should be aware of the possibility of any displacement of the coronary ostium to prevent ostial obstruction at the time of valve replacement or repair.

We report a case of QAV leading to aortic regurgitation. Echocardiographic examinations (especially TEE) play an important role in diagnosing QAV. TTE may be suboptimal in recognizing this malformation. However, as in this case, TEE and RT3DE may lead to a more correct detection of the aortic valve anatomy and the other cardiac defects associated with QAV.

Conflict of interest: none declared

\section{References}

1. Hurwitz LE, Roberts WC. Quadricuspid semilunar valve. Am J Cardiol, 1973; 31: 623-626.

2. Robicsek F, Sanger PW, Daugherty HK, Montgomery CC. Congenital quadricuspid aortic valve with displacement of the left coronary orifice. Am J Cardiol, 1969; 23: 288-290.

3. Tutarel $\mathrm{O}$. The quadricuspid aortic valve: A comprehensive review. J Heart Valve Dis, 2004; 13: 534-537.

4. Formica F, Sangalli F, Ferro O, Paolini G. A rare cause of severe aortic regurgitation: Quadricuspid aortic valve. Interact Cardiovasc Thorac Surg, 2004; 3: 672-674.

5. Feldman BJ, Khandheria BK, Warnes CA, Seward JB, Taylor CL, Tajik AJ. Incidence, description and functional assessment of isolated quadricuspid aortic valves. Am J Cardiol, 1990; 65: 937-938.

6. Armen TA, Vandse R, Bickle K, Nathan N. Three-dimensional echocardiographic evaluation of an incidental quadricuspid aortic valve. Eur J Echocardiogr, 2008; 9: 318-320.

7. Janssens U, Klues HG, Hanrath P. Congenital quadricuspid aortic valve anomaly associated with hypertrophic non-obstructive cardiomyopathy: A case report and review of the literature. Heart, 1997; 78: 83-87.

8. Iglesias A, Oliver J, Munos JE, Nunez L. Quadricuspid aortic valve associated with fibromuscular subaortic stenosis and aortic regurgitation treated by conservative surgery. Chest, 1981; 80: $327-328$ 